\title{
Diversity of Serratia marcescens Strains Associated with Cucurbit Yellow Vine Disease in Georgia
}

\author{
K. R. Besler and E. L. Little, Department of Plant Pathology, University of Georgia, Athens 30602
}

\begin{abstract}
Cucurbit yellow vine disease (CYVD), caused by the squash bug (Anasa tristis)-transmitted bacterium Serratia marcescens, was first identified in Oklahoma and Texas in 1988 and in Georgia in 2012. S. marcescens is a highly diverse species found in many ecological niches. In previous studies, CYVD strains of $S$. marcescens formed a closely related group separate from non-CYVD strains based on biological and molecular characterization techniques. Multilocus sequence analysis (MLSA) of six housekeeping genes and repetitive elements-based polymerase chain reaction (rep-PCR) using the BOX and ERIC primers were used to assess the genetic diversity of CYVD strains of $S$. marcescens collected in

Georgia together with a strain from Texas and seven non-CYVD strains of $S$. marcescens. rep-PCR results revealed genetic diversity among CYVD strains while MLSA results showed a $100 \%$ similarity across the six loci for all but one of the CYVD strains, which differed at the $i c d$ locus by five polymorphisms. For both methods, CYVD strains clustered separately from nonplant-pathogenic $S$. marcescens strains and were most similar to a rice endophyte strain. One CYVD strain isolated from a squash bug shared genetic similarities with non-CYVD strains, and may be the result of a recombination event between CYVD and non-CYVD strains.
\end{abstract}

Cucurbit yellow vine disease (CYVD), caused by the bacterium Serratia marcescens, was first observed on squash (Cucurbita pepo) in Texas and Oklahoma in 1988, and on watermelon (Citrullus lanatus) in Oklahoma in 1991 (Bruton et al. 1998). Confirmation of the causal agent as $S$. marcescens was completed in 2003 (Bruton et al. 2003; Rascoe et al. 2003). CYVD has since been identified in other eastern U.S. states, including Alabama (Sikora et al. 2012), Georgia (Besler and Little 2015), Massachusetts (Wick et al. 2001), and Tennessee (Bost et al. 1999). Disease symptoms include yellowing, stunting, wilting, plant collapse, and a honey-brown discoloration of the phloem in the crown area. Outbreaks of the disease are sporadic and isolated but can cause significant losses, especially when vector populations cannot be adequately managed (Bruton et al. 2003). In Georgia, the disease has been found in squash and pumpkin production in the Piedmont section of the state. CYVD is the only known plant disease vectored by squash bugs (Anasa tristis) (Pair et al. 2004). S. marcescens accumulates in the phloem (Bruton et al. 1998) but, unlike other phloem-limited bacteria, is easily cultured on standard microbiological media. The unique features and recent emergence of CYVD raises questions regarding the origins of this bacterium-plant-insect complex, and the relationship of Georgia CYVD strains to previously characterized $S$. marcescens strains.

S. marcescens is an ecologically and genetically diverse bacterial species in the family Enterobacteriaceae. S. marcescens strains survive as water or soil saprophytes, rhizobacteria, insect pathogens, plant endophytes, and opportunistic human pathogens (Bruton et al. 2003; Tan et al. 2001; Wei et al. 1996). Studies have shown that CYVD strains of $S$. marcescens are phenotypically and genotypically distinct from $S$. marcescens strains isolated from other ecological niches (Rascoe et al. 2003; Zhang et al. 2003). CYVD strains of $S$. marcescens, as well as the rice endophyte R01-A, are nonpigmented, whereas the bacterial colonies of most $S$. marcescens strains are red in color due to the production of prodigiosin. Although $S$. marcescens has been identified as the causal agent of soft rot in

Corresponding author: E. L. Little; E-mail: elittle@uga.edu

Current address of K. Besler: Department of Neurobiology and Behavior, Cornell University, Ithaca, NY 14853.

Accepted for publication 8 August 2016.

(C) 2017 The American Phytopathological Society pepper (Gillis et al. 2014) and whorl rot in corn (Wang et al. 2015), the associated pathogenic strains produce pigment and are genetically distant from CYVD strains. Fatty acid methyl ester analysis indicated a significant difference between CYVD strains and other Serratia spp. and, in some cases, placed CYVD strains closer to $S$. fonticola, S. plymuthica, and S. odorifera than to S. marcescens (Rascoe et al. 2003). In the same study, carbon substrate utilization assays (BIOLOG, Inc.) revealed that, whereas non-CYVD strains were accurately identified as $S$. marcescens, the CYVD strains tested were metabolically deficient in utilizing 30 substrates when compared with the non-CYVD strains, and an accurate species match for CYVD strains was not possible using BIOLOG. One limitation in the phenotypic characterization of CYVD is the lack of an efficient pathogenicity test. Vascular browning but no plant collapse was observed in no more than $50 \%$ of artificially inoculated plants after 6 weeks of incubation, and the efficiency was even less when plants were inoculated using squash bugs that were fed the bacterium (Bruton et al. 2003). CYVD strains contain unique sequences not found in non-CYVD stains, and CYVD strain-specific polymerase chain reaction (PCR) primers have been developed (Zhang et al. 2005); however, the genetic determinants for pathogenicity are not yet known.

PCR using primers that anneal to repetitive extragenic elements (rep-PCR) is a relatively inexpensive and rapid method for differentiating closely related bacterial species, subspecies, and pathovars (Bereswill et al. 1994; Little et al. 1998; Louws et al. 1999). Previous rep-PCR analyses indicated that CYVD strains of S. marcescens isolated from different cucurbit hosts and states in the eastern United States were identical and formed a group that was separate from all other $S$. marcescens strains. The most closely related strains using this method included three rice endophytes (R01-A, R02-A, and R03-A), a cotton endophyte (G01-A), and a human pathogen (H02-A) (Zhang et al. 2003). This relationship between strains was further supported by the results of DNA-DNA hybridization (DDH) where Zhang et al. (2003) found that the divergence at the genomic level between CYVD strains and non-CYVD strains ranged from 69 to $90 \%$ while the change in melting temperature $\left(\Delta \mathrm{T}_{\mathrm{m}}\right)$ ranged from 1.0 to $3.5^{\circ} \mathrm{C}$.

Repetitive sequences are dispersed throughout bacterial genomes (Lupski and Weinstock 1992; Versalovic et al. 1994), although the results of rep-PCR give no indication of where the variation lies in the genome. In addition, rep-PCR results are limited by reproducibility and data portability between labs (Patchanee et al. 2012). Sequence-based approaches - in particular multilocus sequence typing (MLST) - are now commonly used to characterize bacterial 
strains due to the high reproducibility of results, ease of interpretation, and ability to enter the results of individual strains into a shared database (Maiden et al. 1998). MLST has been useful when typing clinical or plant-pathogenic strains that are very closely related (Bull et al. 2011; Feng et al. 2009; Maiden et al. 1998). MLST and sequences deposited in the Plant-Associated Microbes Database (Almeida et al. 2010) were used to accurately identify the pathovar of Pseudomonas syringae strains isolated from diseased plants, and confirmed that MLST results reflected the species and subspecies relationships previously determined using phenotypic and genotypic methods, including DDH (Bull et al. 2011).

With highly diverse species such as $S$. marcescens, MLST can result in an overabundance of sequence types, making it difficult to

Table 1. Source, collection year, and geographic origin of Serratia spp. strains used in this study

\begin{tabular}{|c|c|c|c|}
\hline Species, strains ${ }^{\mathbf{a}}$ & $\begin{array}{l}\text { Source, } \\
\text { host }\end{array}$ & $\begin{array}{c}\text { Date } \\
\text { collected }\end{array}$ & $\begin{array}{l}\text { Geographic } \\
\text { origin }\end{array}$ \\
\hline \multicolumn{4}{|l|}{ Serratia marcescens } \\
\hline \multicolumn{4}{|l|}{ Non-CYVD } \\
\hline $\begin{array}{l}\text { ATCC } 13880 \\
\text { (type) }^{\mathrm{b}}\end{array}$ & Pond water & Unknown & Unknown \\
\hline I06-A ${ }^{b}$ & $\begin{array}{l}\text { Unknown } \\
\text { insect }\end{array}$ & 1961 & California \\
\hline On- $01^{c}$ & $\begin{array}{l}\text { Onion } \\
\text { endophyte }\end{array}$ & 2013 & Georgia \\
\hline $\begin{array}{l}\text { R01-A } \\
\quad(\text { IRBG501) }\end{array}$ & $\begin{array}{l}\text { Rice } \\
\text { endophyte }\end{array}$ & Unknown & Philippines \\
\hline $\begin{array}{l}\text { SM39 } \\
\text { (AP013063.1) }\end{array}$ & Human & 1999 & Japan \\
\hline $\begin{array}{l}\text { WW4 } \\
\text { (CP003959.1) }\end{array}$ & Paper machine & 2013 & Taiwan \\
\hline $\mathrm{W} 11^{\mathrm{c}}$ & $\begin{array}{l}\text { Melon } \\
\text { endophyte }\end{array}$ & 2013 & Georgia \\
\hline \multicolumn{4}{|l|}{ CYVD } \\
\hline W01-A & Watermelon & 1999 & Texas \\
\hline $\mathrm{P} 01$ & Pumpkin & 2012 & Oconee County, GA \\
\hline $\mathrm{P} 02$ & Pumpkin & 2012 & Oconee County, GA \\
\hline $\mathrm{P} 03$ & Pumpkin & 2012 & Oconee County, GA \\
\hline P04 & Pumpkin & 2012 & Oconee County, GA \\
\hline $\mathrm{P} 05$ & Pumpkin & 2013 & Oconee County, GA \\
\hline P06 & Pumpkin & 2013 & Oconee County, GA \\
\hline S5 & Pumpkin & 2012 & Oconee County, GA \\
\hline S02 & $\begin{array}{r}\text { Summer } \\
\text { squash }\end{array}$ & 2013 & $\begin{array}{l}\text { Oglethorpe County, } \\
\text { GA }\end{array}$ \\
\hline S04 & $\begin{array}{r}\text { Summer } \\
\text { squash }\end{array}$ & 2013 & $\begin{array}{l}\text { Oglethorpe County, } \\
\text { GA }\end{array}$ \\
\hline SB01 & Squash bug & 2013 & Oconee County, GA \\
\hline SB02 & Squash bug & 2013 & Oconee County, GA \\
\hline SB03 & Squash bug & 2013 & Oconee County, GA \\
\hline Z01 & Zucchini & 2012 & Oconee County, GA \\
\hline Z02 & Zucchini & 2012 & Oconee County, GA \\
\hline Z04 & Zucchini & 2013 & Clarke County, GA \\
\hline Z05 & Zucchini & 2013 & Clarke County, GA \\
\hline Z06 & Zucchini & 2013 & Oconee County, GA \\
\hline Z07 & Zucchini & 2013 & Oconee County, GA \\
\hline Z08 & Zucchini & 2013 & Oconee County, GA \\
\hline Z09 & Zucchini & 2013 & Oconee County, GA \\
\hline $\mathrm{Z} 10$ & Zucchini & 2013 & Oconee County, GA \\
\hline $\mathrm{Z} 12$ & Zucchini & 2013 & Oconee County, GA \\
\hline Z13 & Zucchini & 2013 & Oconee County, GA \\
\hline $\begin{array}{l}\text { S. plymuthica } \\
\text { (CP006566.1) }\end{array}$ & $\begin{array}{l}\text { Pumpkin } \\
\text { endophyte }\end{array}$ & 2009 & Austria \\
\hline
\end{tabular}

a Accession numbers are included for strains where sequence data were obtained from GenBank CYVD = cucurbit yellow vine disease strains, ATCC $=$ American Type Culture Collection, and IRBG $=$ The International Rice Research Institute Bacterial Germplasm, IRRI, Philippines.

${ }^{\mathrm{b}}$ Strains provided by J. Fletcher, Oklahoma State University.

${ }^{\mathrm{c}}$ Strains provided by B. Dutta, University of Georgia. draw meaningful conclusions about evolutionary histories. MLST identified 121 unique sequence types when used to characterize 135 strains of Streptococcus mutans, although many individual loci were identical across multiple strains (Do et al. 2010). For this reason, multilocus sequence analysis (MLSA) is often used separately or in conjunction with MLST. MLSA is similar to MLST, except that the analysis is based directly on DNA sequences instead of allele numbers and sequence type (Young et al. 2008). This method is especially useful for the CYVD-associated strains of Serratia marcescens, which have significant sequence differences when compared with non-CYVD strains. The objectives for this study were to use MLSA together with rep-PCR to assess the genetic diversity of CYVD-associated strains of $S$. marcescens isolated from squash bug and cucurbit hosts in Georgia, evaluate the potential of MLSA to build a genetic database of $S$. marcescens strains, and further clarify the genetic relationships within and between CYVD and nonCYVD strains of $S$. marcescens.

\section{Materials and Methods}

Bacterial strains and DNA extraction. In all, 33 strains of Serratia spp. were examined in this study (Table 1), of which 32 were $S$. marcescens and one was $S$. plymuthica. Twenty-four of the $S$. marcescens strains were CYVD-associated. All CYVD strains were sampled in Georgia, except for W01-A, which was previously sampled from watermelon in Texas. Georgia CYVD strains were isolated from individual CYVD-symptomatic pumpkin (Cucurbita pepo) or summer squash (C. pepo) plants, or from individual squash bugs collected at or near a site with infected plants. The lower stems of symptomatic plants were surface sterilized for $2 \mathrm{~min}$ in $0.83 \% \mathrm{NaOCl}$, and small sections (approximately $0.1 \mathrm{~g}$ ) of discolored phloem tissue were excised. The tissue was macerated using a microtube pestle in a 1.5-ml Eppendorf tube containing $1.0 \mathrm{ml}$ of $0.01 \mathrm{M}$ phosphate buffered saline (PBS), and spread onto Luria-Bertani (LB) agar plates. For squash bug isolations, bugs were surface sterilized for $2 \mathrm{~min}$ in $0.83 \% \mathrm{NaOCl}$ before the head and prothorax were removed and macerated in a 1.5-ml Eppendorf tube containing $1 \mathrm{ml}$ of PBS. Strains W11 and On-01 were endophytes isolated in Georgia from watermelon and onion, respectively. The type strain (American Type Culture Collection [ATCC] 13880) was isolated from pond water. R01-A was a rice endophyte and I06-A was an insect pathogen. Sequence data for strains SM39 (National Center for Biotechnology Information [NCBI] accession AP013063.1), WW4 (NCBI accession CP003959.1), and S. plymuthica (NCBI accession CP006566.1) were obtained from GenBank (Benson et al. 2012).

Bacterial strains were stored in $15 \%$ glycerol at $-80^{\circ} \mathrm{C}$. For genomic DNA extraction, single colonies from 3-day-old LB agar plates were grown in $5 \mathrm{ml}$ of LB broth for $24 \mathrm{~h}$ at $28^{\circ} \mathrm{C}$ on an orbital shaker at $200 \mathrm{rpm}$. Genomic DNA was extracted following the manufacturer's protocol using a DNeasy Blood and Tissue Kit (Qiagen). DNA concentrations were estimated spectrophotometrically (NanoDrop Technologies).

Strain identification. Bacterial colonies isolated from symptomatic cucurbit plants were compared with a known CYVD strain for morphology on LB, presence of cytochrome oxidase using BBL DrySlide Oxidase Slides (Becton Dickinson), and anaerobic growth using Hugh and Leifson's oxidative-fermentative medium (Hugh and Leifson 1953). Substrate utilization profiles using BIOLOG GN2 MicroPlates (BIOLOG) for gram-negative bacteria were determined for CYVD $S$. marcescens strains P01 and W01-A, and for the non-CYVD rice endophyte R01-A strain.

The identity of $S$. marcescens strains was confirmed using speciesspecific primers YV1 (GGGAGCTTGCTCCCCGG) and YV4 (AACGTCAATTGATGAACGTATTAAGT), which amplify a portion of the16S ribosomal DNA (rDNA) gene (Zhang et al. 2005). The identity of CYVD strains was confirmed using the strain-specific primers A79F (CCAGGATACATCCCATGATGAC) and A79R (CATATTACCTGATGCTCCTC), which target unique CYVD strain sequences (Zhang et al. 2005).

Pathogenicity was determined for CYVD strains P01, SB03, and W01-A based on previous methods (Bruton et al. 2003). Bacterial 
strains were grown in $\mathrm{LB}$ for $24 \mathrm{~h}$ at $28^{\circ} \mathrm{C}$ on an orbital shaker at $200 \mathrm{rpm}$ and resuspended in $1 \times \mathrm{PBS}$ at a concentration of $1 \times 10^{8}$ CFU/ml. Pumpkin plants ('New England Pie'; Johnny's Seed) were inoculated at the expanded cotyledon stage by placing $20 \mu \mathrm{l}$ of the bacterial suspension or $1 \times$ PBS at the junction of the stem and cotyledon. An inoculation fork was used to make 10 penetrations through the inoculum, both cotyledons, and the apical meristem. Ten plants were inoculated for each bacterial strain and the negative control. Plants were transferred to $25-\mathrm{cm}$-diameter pots and maintained in a greenhouse. At 8 weeks, plants were evaluated for symptom development and isolations were attempted from all plants as described above.

MLSA. Housekeeping genes (HKG) adenylate kinase ( $a d k)$, fumarate hydratase (fumC), gyrase subunit $\beta$ ( $g y r B)$, isocitrate/ isopropylmalate dehydrogenase $(i c d)$, malate dehydrogenase $(m d h)$, and ATP/GTP binding motif ( $\mathrm{rec} A$ ) were used in the MLSA using a scheme developed for the enteric bacterium, Escherichia coli (Wirth et al. 2006). Candidate genes were screened by comparing nucleotide polymorphisms between $S$. marcescens WW4 (NCBI accession CP003959.1) and S. marcescens Db11 (NCBI accession HG326223.1) at candidate loci using the Basic Local Alignment Search Tool (BLAST) (Altschul et al. 1990). Selected genes had a similarity between 96 and $98 \%$ when comparing the two available sequences, which corresponded to 8 to 20 polymorphisms per 500 - to 600-bp gene fragment. Primers for each gene were designed using Primer3 primer design software (Untergasser et al. 2012) to amplify fragment lengths between 507 and $634 \mathrm{bp}$ from the complete genome of S. marcescens WW4 (Table 2).

A Mastercycler Personal (Eppendorf) was used for PCR on 30 strains of $S$. marcescens using primers designed from the six HKG. Extracted total DNA was used at $100 \mathrm{ng} /$ reaction with $12.5 \mu \mathrm{l}$ of Taq PCR Master Mix (Qiagen), $1.25 \mu \mathrm{l}$ of $10 \mu \mathrm{M}$ forward primer, and $1.25 \mu \mathrm{l}$ of $10 \mu \mathrm{M}$ reverse primer in a total reaction volume of $25 \mu \mathrm{l}$. PCR was performed using the following amplification conditions: $5 \mathrm{~min}$ at $95^{\circ} \mathrm{C} ; 30$ cycles of $30 \mathrm{~s}$ at $95^{\circ} \mathrm{C}, 40 \mathrm{~s}$ at $60^{\circ} \mathrm{C}$, and $60 \mathrm{~s}$ at $72^{\circ} \mathrm{C}$; and 1 final extension cycle of $5 \mathrm{~min}$ at $72^{\circ} \mathrm{C}$. For the $i c d$ and $r e c A$ genes, an annealing temperature of $55^{\circ} \mathrm{C}$ was used instead of $60^{\circ} \mathrm{C}$. PCR products were electrophoretically separated in a $1.5 \%$ GenePure agarose gel (Bioexpress) in 1× Tris-acetate-EDTA (TAE) buffer and stained with ethidium bromide. PCR products that yielded amplicons of expected length were prepared for sequencing using a QIAquick PCR Purification Kit (Qiagen). Sanger sequencing was performed by the University of Georgia's Georgia Genomics Facility using a 3730xl 96-capillary DNA Analyzer (Applied Biosystems).

Sequence analysis. The sequences for the six HKG fragments were visualized and aligned using Geneious v7.1.4. (Biomatters). Phylogenetic and molecular evolutionary analyses were conducted using MEGA, version 6 (Tamura et al. 2013). The sequences were concatenated, and neighbor-joining trees were constructed based on 3,001 bp. A neighbor-joining tree was also constructed for the icd gene to capture the unique variability among CYVD strains at this locus. The percentage of replicate trees containing the same taxa cluster pattern was calculated using a bootstrap test with 500 replicates. The evolutionary distances were described as the number of base pair substitutions per site and were computed using the maximum composite likelihood method. Sequences of the six HKG were deposited in the NCBI GenBank database with the following accession numbers: fum $C$, KU559020 to KU559048; $m d h$, KU559049 to KU559077; adk, KU559078 to KU559106; recA, KU559107 to KU559135; gyrB, KU559106 to KU559164; and icd, KU559165 to KU559193.

rep-PCR. DNA of $30 \mathrm{~S}$. marcescens strains was subjected to repPCR with the BOXA1R primer (BOX-PCR) and the ERIC1R and ERIC2 primers (ERIC-PCR). Extracted total DNA was used at $150 \mathrm{ng} /$ reaction with 1 PuReTaq Ready-To-Go PCR bead (GE Healthcare), $1.5 \mu \mathrm{l}$ of $25 \mu \mathrm{M}$ BOX-A1R primer or $1.5 \mu \mathrm{l}$ of $25 \mu \mathrm{M}$ ERIC1R primer and $1.5 \mu \mathrm{l}$ of $25 \mu \mathrm{M}$ ERIC2 primer in a total reaction volume of $25 \mu \mathrm{l}$. PCR was performed on a Mastercycler Personal (Eppendorf) using the following amplification conditions: $2 \mathrm{~min}$ at $95^{\circ} \mathrm{C} ; 30$ cycles of $3 \mathrm{~s}$ at $94^{\circ} \mathrm{C}, 30 \mathrm{~s}$ at $92^{\circ} \mathrm{C}$, $1 \mathrm{~min}$ at $50^{\circ} \mathrm{C}$, and $8 \mathrm{~min}$ at $65^{\circ} \mathrm{C}$; and 1 final extension cycle of 8 min at $65^{\circ} \mathrm{C}$. PCR fragments were electrophoretically separated in $1.5 \%$ GenePure agarose gels (Bioexpress) in $1 \times$ TAE at $70 \mathrm{~V}$ for $7.5 \mathrm{~h}$ at $4^{\circ} \mathrm{C}$. Gels were stained with ethidium bromide and bands were visualized using a UVP Biospectrum 300 Imaging System (UVP LLC).

Comparisons of DNA fingerprint patterns were performed using BioNumerics software (v2.0; Applied-Maths). rep-PCR using each primer set was repeated at least three times and only repeatable banding patterns were used for phylogenetic analysis. Fingerprint profiles were aligned and bands were scored visually as positive or negative. Dendrograms based on banding patterns were constructed using the unweighted pairwise group method with arithmetic mean cluster analysis and Dice's coefficient of similarity (Dice 1945).

\section{Results}

Strain identification. CYVD strains formed smooth, circular, convex, translucent, and nonpigmented colonies on LB agar, and were oxidase negative and facultative anaerobic. Substrate utilization profiles constructed using BIOLOG identified the rice endophyte strain R01-A as S. marcescens with a probability of $100 \%$ and a similarity ranking of 0.866 , with a similarity ranking of 0.500 or greater being required for a species identification. CYVD strains P01 and W01-A yielded identical substrate utilization profiles and were identified as most similar to Tatumella ptyseos and S. marcescens, with similarity rankings of 0.154 and 0.120 , respectively. Although W01-A and P01 were able to utilize 18 of the 96 substrates, R01A was able to utilize 74 of the 96 substrates, including the 18 that were consumed by the CYVD-associated strains.

S. marcescens-specific PCR primers YV1 and YV4 amplified the expected 452-bp fragment from all $S$. marcescens strains. The CYVD strain-specific PCR primers A79F and A79R amplified the expected 338-bp fragment only from the CYVD strains. Plants inoculated with

Table 2. Functions, primer sequences, and fragment lengths of housekeeping genes used in multilocus sequence analysis

\begin{tabular}{|c|c|c|c|}
\hline Gene name & Gene function & Primer sequences ( $\left(5^{\prime}\right.$ to $\left.3^{\prime}\right)$ (forward, reverse) & Gene fragment length (bp) \\
\hline \multirow[t]{2}{*}{$a d k$} & Adenylate kinase & gggcgctggtaaaggtactc & 536 \\
\hline & $\ldots$ & ctgccgcttctttgctgtag & $\ldots$ \\
\hline \multirow[t]{2}{*}{ fum $C$} & Fumarate hydratase & gcgcatttccgtatttcctc & 634 \\
\hline & $\ldots$ & actccggatgggtattcagg & $\ldots$ \\
\hline \multirow[t]{2}{*}{ gyrB } & Gyrase subunit $\beta$ & gcggtaaattcgacgacaac & 567 \\
\hline & $\ldots$ & tcatcgeggtacggaaac & $\ldots$ \\
\hline \multirow[t]{2}{*}{$i c d$} & Isocitrate/isopropylmalate dehydrogenase & cgttactaccagggcactcc & 528 \\
\hline & $\ldots$ & gtcgecgttcaggttcatac & $\ldots$ \\
\hline \multirow[t]{2}{*}{$m d h$} & Malate dehydrogenase & ggacgtggtgctgatttcc & 507 \\
\hline & $\ldots$ & accagagacagaccgaaacg & $\ldots$ \\
\hline \multirow[t]{2}{*}{ recA } & ATP/GTP binding motif & gcgetggatcctatctatgc & 508 \\
\hline & $\ldots$ & cttcgccgtacatgatttgg & $\ldots$ \\
\hline
\end{tabular}


CYVD strains exhibited limited leaf yellowing but no wilting. CYVD strains of $S$. marcescens were recovered from 6 of 10,5 of 10 , and 2 of 10 plants that were inoculated with W01-A, P01, and SB03, respectively. In all cases, the presence of phloem discoloration was positively correlated with pathogen recovery from inoculated plants. S. marcescens was not recovered from any plants with normal-appearing phloem or the PBS negative controls.

MLSA. Phylogenetic trees constructed using the neighbor-joining method revealed that $S$. marcescens CYVD strains formed a wellsupported cluster and were separate from non-CYVD strains with a bootstrap support value of $96 \%$ (Fig. 1A). With the exception of SB03, which was one of three strains isolated from squash bugs, all CYVD strains had identical sequences at all six loci.

Genetic diversity was higher among non-CYVD strains (Fig. 1A and B; Table 3). The number of polymorphic sites per gene among the seven non-CYVD strains in this study ranged from 10 to 31 , with a mean of 19. On-01 (onion endophyte) and W11 (watermelon endophyte) shared identical sequences across all six gene fragments and clustered with I06-A (insect pathogen) and WW4 (from a paper machine). SM39, a human clinical isolate, showed the most divergence of all non-CYVD strains. MLSA indicated that strain R01-A, a rice endophyte, shared more sequence similarities with CYVD strains than with non-CYVD strains. R01-A differed from CYVD strains by an average of 6 polymorphisms per gene fragment and from other non-CYVD strains by an average of 14 polymorphisms per gene fragment.
SB03 shared identical sequences with CYVD strains at five of the six loci but the sequence at the icd locus contained five polymorphisms not present in the other 23 CYVD strains. At this locus, SB03 shared an identical sequence with ATCC 13880, which was isolated from pond water. The neighbor-joining method was used with the $508 \mathrm{bp}$ from the icd gene to construct a separate phylogenetic tree (Fig. 1B). The icd tree showed that SB03 and ATCC 13880 were more similar in sequence to the R01-A rice endophyte and the human SM39 strain than to the other CYVD strains. For the other five loci, SB03 differed from ATCC 13880 by an average of 15 nucleotide polymorphisms, with a range of 6 to 26 polymorphisms.

rep-PCR. BOX-PCR revealed variation among CYVD $S$. marcescens strains (Fig. 2). With the exception of SB03, CYVD strains of $S$. marcescens formed a group separate from all non-CYVD strains. CYVD strain SB03 shared similarities with the non-CYVD group and was most closely related to ATCC 13880. CYVD strain W01-A, which was isolated from a watermelon plant in Texas, was within the CYVD group but was not genetically identical to any of the Georgia strains. Based on BOX-PCR banding patterns, endophytic strains On-01 and W11 were identical and formed a larger group that contained the insect pathogen strain I06-A. Among the non-CYVD strains, the rice endophyte R01-A was most similar to the CYVD strains using both ERIC- and BOX-PCR.

The dendrogram constructed using ERIC-PCR showed less apparent genetic variation among CYVD S. marcescens strains (Fig. 3).
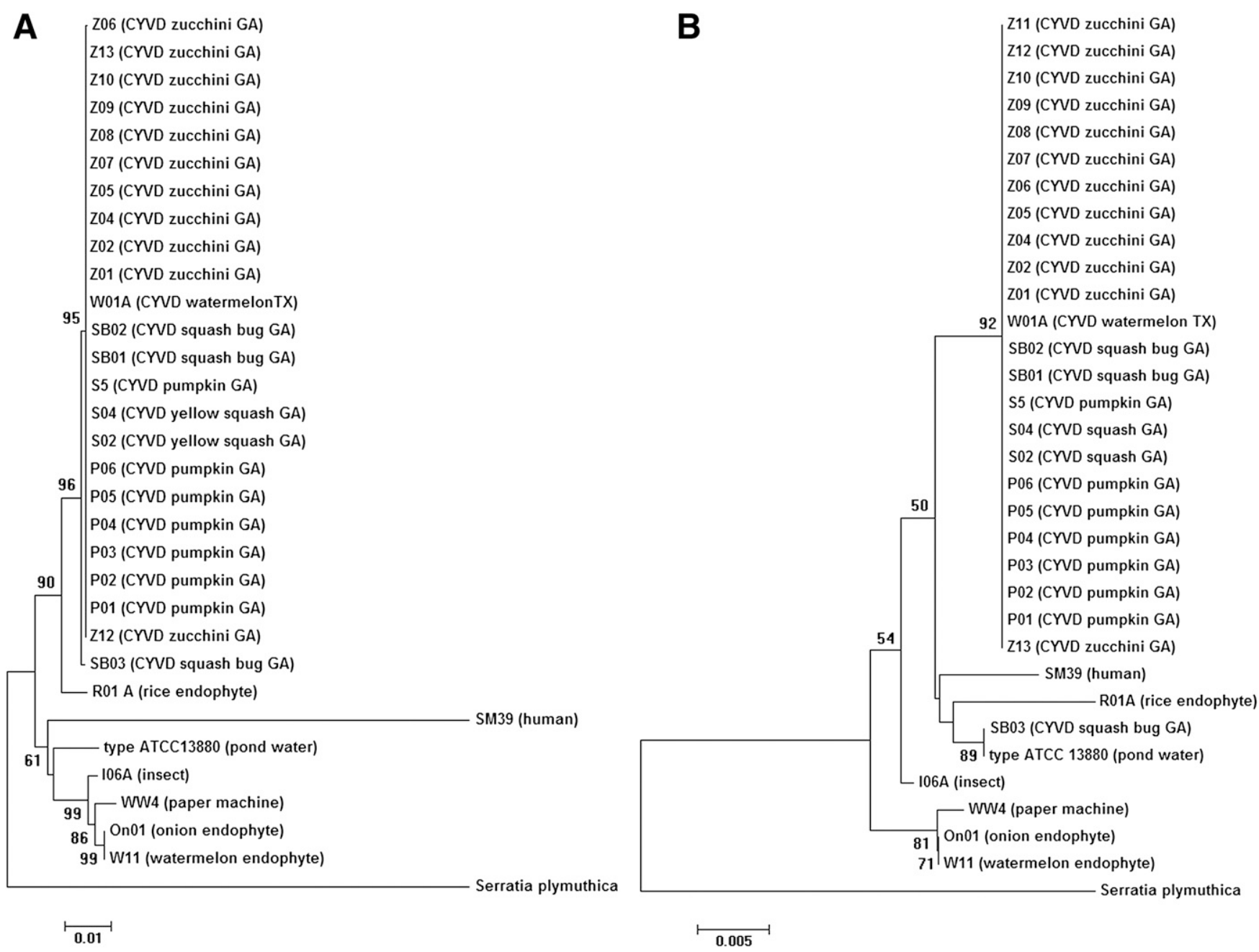

Fig. 1. Phylogeny of 31 Serratia marcescens strains and one S. plymuthica strain using multilocus sequence analysis (MLSA) and computed using the neighbor-joining method. The tree is drawn to scale, with branch lengths in the same units as those of the evolutionary distances used to infer the phylogenetic tree. The evolutionary distances were computed in MEGA6 (Tamura et al. 2013) using the maximum composite likelihood method and are in the units of the number of base substitutions per site. Bootstrap values greater than $50 \%$ are depicted next to each branch. A, Tree was constructed using 3,001 bp from six concatenated housekeeping genes (adk, fumC, gyrB, icd, mdh, and $\operatorname{rec} \mathrm{A}$ ), and $\mathrm{B}$, tree was constructed using $508 \mathrm{bp}$ from the icd gene. Source of strain given in parentheses. CYVD = cucurbit yellow vine disease strains of $S$. marcescens. 
Table 3. Number of base substitutions per site between concatenated sequences used in multilocus sequence analysis ${ }^{\mathrm{a}}$

\begin{tabular}{|c|c|c|c|c|c|c|c|c|c|c|}
\hline & Strain & 1 & 2 & 3 & 4 & 5 & 6 & 7 & 8 & 9 \\
\hline 1 & I06A & $\ldots$ & $\ldots$ & $\ldots$ & $\ldots$ & $\ldots$ & $\ldots$ & $\ldots$ & $\ldots$ & $\ldots$ \\
\hline 2 & On01 & 0.005 & $\ldots$ & $\ldots$ & $\ldots$ & $\ldots$ & $\ldots$ & $\ldots$ & $\ldots$ & $\ldots$ \\
\hline 3 & CYVD & 0.025 & 0.027 & $\ldots$ & $\ldots$ & $\ldots$ & $\ldots$ & $\cdots$ & $\cdots$ & $\cdots$ \\
\hline 4 & R01A & 0.026 & 0.028 & 0.011 & $\ldots$ & $\ldots$ & $\ldots$ & $\ldots$ & $\ldots$ & $\ldots$ \\
\hline 5 & SB03 & 0.025 & 0.027 & 0.001 & 0.010 & $\ldots$ & $\ldots$ & $\ldots$ & $\ldots$ & $\ldots$ \\
\hline 6 & Serratia plymuthica & 0.129 & 0.128 & 0.129 & 0.129 & 0.130 & $\ldots$ & $\ldots$ & $\ldots$ & $\ldots$ \\
\hline 7 & SM39 & 0.108 & 0.111 & 0.114 & 0.117 & 0.114 & 0.255 & $\ldots$ & $\ldots$ & $\ldots$ \\
\hline 8 & ATCC13880 & 0.020 & 0.022 & 0.025 & 0.026 & 0.024 & 0.131 & 0.113 & $\ldots$ & $\ldots$ \\
\hline 9 & W11 & 0.005 & 0.000 & 0.027 & 0.028 & 0.027 & 0.128 & 0.111 & 0.022 & $\ldots$ \\
\hline 10 & WW4 & 0.008 & 0.007 & 0.030 & 0.030 & 0.030 & 0.126 & 0.111 & 0.022 & 0.007 \\
\hline
\end{tabular}

a Analyses were conducted using the maximum composite likelihood model. CYVD = identical sequence shared by all CYVD strains except SB03. All positions containing gaps and missing data were eliminated. There were a total of 3,059 positions in the final dataset. Evolutionary analyses were conducted in MEGA6 (Tamura et al. 2013).

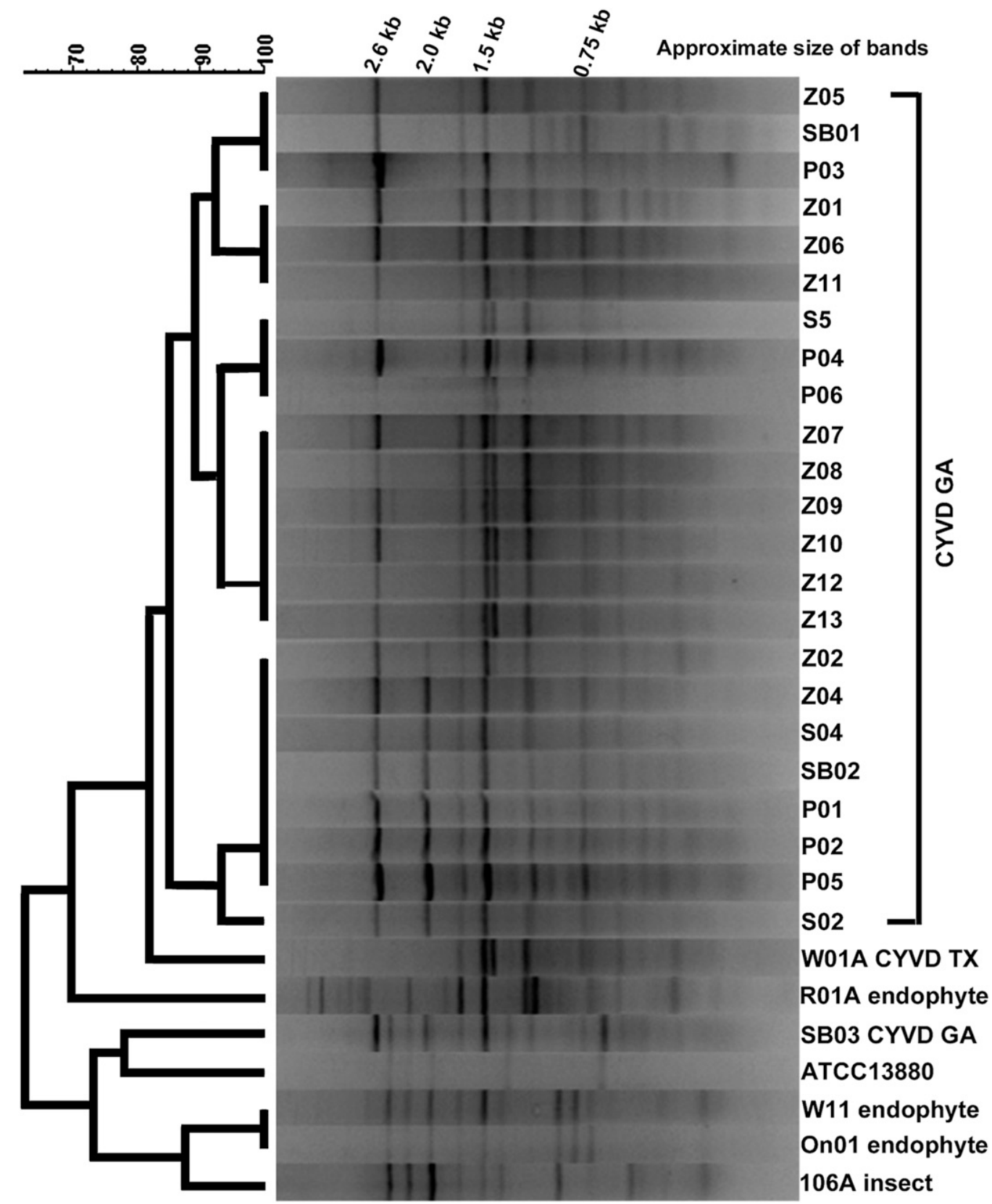

Fig. 2. Dendrogram constructed using unweighted pairwise group method with arithmetic mean cluster analysis and Dice's coefficient from the DNA fragment banding patterns for Serratia marcescens strains (shown) using repetitive sequence-based polymerase chain reaction with BOX-A1R primer. Size of fragments approximated from the 1-kb DNA ladder (not shown). Source of cucurbit yellow vine disease (CYVD) strains: Z01 to Z13, Georgia zucchini; P01 to P06, Georgia pumpkin; S5, S02, and S04, Georgia squash; SB01, SB02, and SB03, Georgia squash bug; and W01-A, Texas watermelon. 
Fewer fragments were generated than with BOX-PCR, with four to seven fragments per strain. ERIC-PCR yielded identical banding patterns for 24 of 25 CYVD strains. The only exception was SB03, which had two additional bands and shared an identical banding pattern with ATCC 13880. The 24 identical CYVD strains formed a group separate from all other $S$. marcescens strains (Fig. 3). SB03 and ATCC 13880, together with rice endophyte R01-A, were most closely aligned to the CYVD cluster. Similar to BOX-PCR, endophytes W11 and On-01 had identical banding patterns using ERIC-PCR and formed a separate group that contained the insect pathogen I06-A.

\section{Discussion}

In this study, both MLSA and rep-PCR analyses revealed genetic diversity among CYVD strains. Previous genetic characterization of CYVD strains from Oklahoma, Texas, Arkansas, and Massachusetts using rep-PCR and the BOX and ERIC primers revealed no differences in banding patterns (Zhang et al. 2003). In addition, this is the first genetic characterization of CYVD strains of $S$. marcescens from Georgia and the first characterization of CYVD strains using both rep-PCR and MLSA.

Using MLSA, CYVD strains of $S$. marcescens formed one cluster that was separate from all non-CYVD strains, and only 1 strain (SB03) of the 24 CYVD strains examined in this study was genetically different. This variation was due to polymorphisms that occurred only at the icd locus. Similar genetic uniformity was discovered when hypervirulent strains of Neisseria meningitides were examined (Maiden et al. 1998). In that study, six loci were sequenced and found to be nearly identical in the recently emerged hypervirulent strains, whereas nonpathogenic strains exhibited a greater diversity, characterized by numerous unique allele combinations. The genetic similarities revealed by MLSA suggests that CYVD-associated strains of $S$. marcescens may have emerged relatively recently and are derived from a single common ancestor (Byun et al. 1999; Maiden et al. 1998).

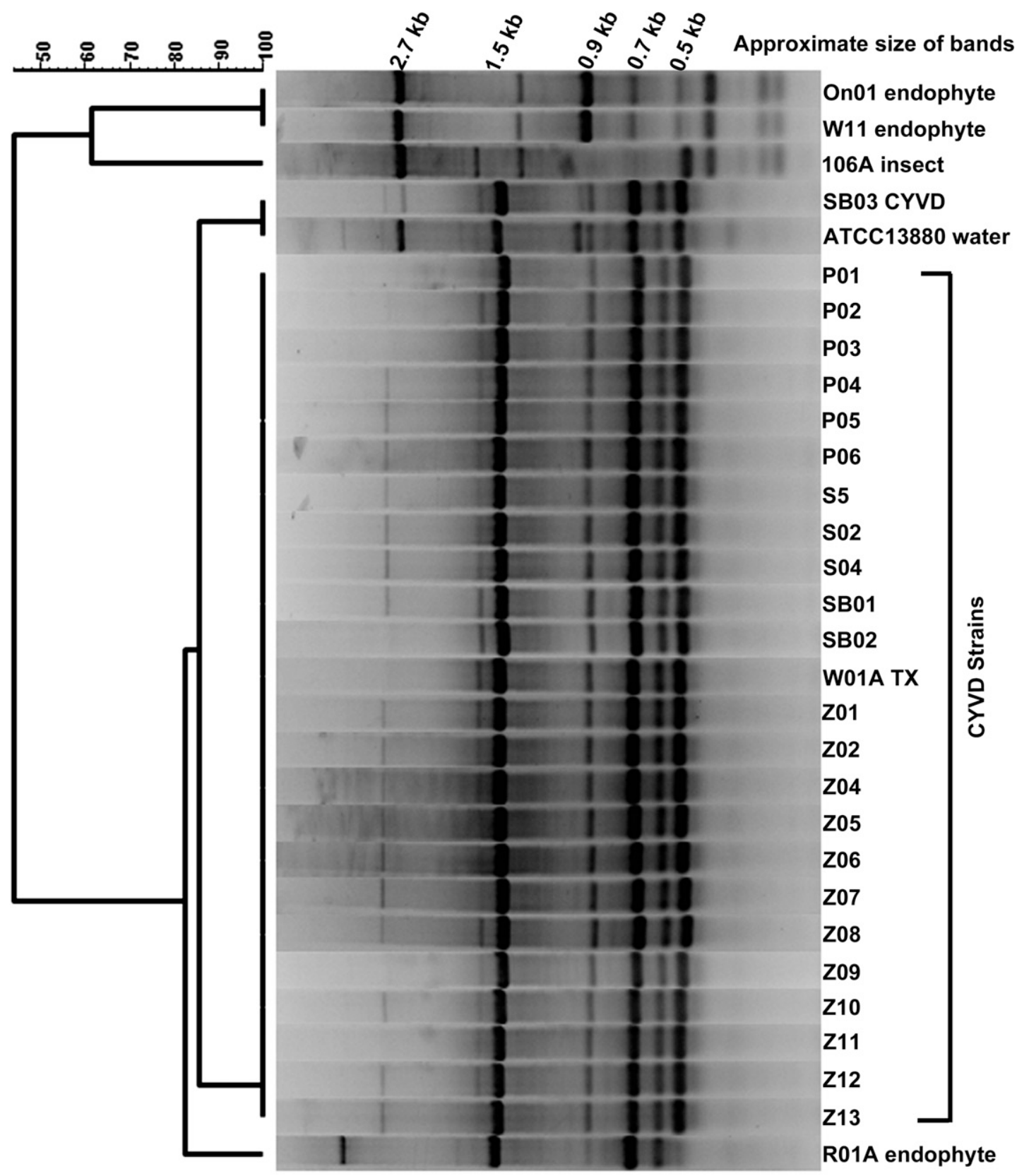

Fig. 3. Dendrogram constructed using unweighted pairwise group method with arithmetic mean cluster analysis and Dice's coefficient from the DNA fragment banding patterns for Serratia marcescens strains (shown) using repetitive sequence-based polymerase chain reaction with the ERIC1R and ERIC2 primers. Size of fragments approximated from the 1-kb DNA ladder (not shown). Source of cucurbit yellow vine disease (CYVD) strains: Z01 to Z13, Georgia zucchini; P01 to P06, Georgia pumpkin; S5, S02, and S04, Georgia squash; SB01, SB02, and SB03, Georgia squash bug; and W01-A, Texas watermelon. 
The MLSA results showed that the endophyte strain R01-A is more similar to CYVD strains than it is to non-CYVD strains; this may suggest that CYVD strains could have arisen from a plant endophyte. In addition, both CYVD strains and R01-A colonies are nonpigmented whereas all other $S$. marcescens strains tested produced the red pigment prodigiosin. The MLSA results supported previous genetic characterization of $S$. marcescens, including rep-PCR, 16S rDNA, and groE gene sequencing, and DDH, which showed that the rice endophyte R01-A was closely related to CYVD strains (Rascoe et al. 2003; Zhang et al. 2003). In a later study using subtractive hybridization, R01-A and another closely related rice endophyte, R02-A, shared the greatest number of common sequences with a CYVD strain than all other non-CYVD strains tested, and two gene clusters were identified in CYVD strains that were absent in the rice endophytes (Zhang et al. 2005). However, the results of BIOLOG revealed that, although RO1-A was accurately identified as $S$. marcescens, CYVD strains were not able to utilize most of the same substrates as R01-A and could not be identified using this method. The reduced substrate utilization may be linked to the unique capacity of CYVD strains to be vectored by squash bugs or reside in the phloem of cucurbits. Some virulence traits in plant and human pathogens may be derived from fitness traits (Morris et al. 2009; Reguera and Kolter 2005) developed for survival in other environmental niches, and the unique phenotypic and genetic characteristics that make CYVD strains pathogenic may have a function in a nonagricultural niche.

With the exception of CYVD strain SB03, both BOX- and ERICPCR also placed the CYVD-associated strains of $S$. marcescens in a separate clade from non-CYVD strains. rep-PCR revealed more genetic variation among CYVD strains than did MLSA. BOX-PCR had more discriminatory power than ERIC-PCR and divided Georgia CYVD-associated strains into three subgroups, each containing between six and nine strains. The hosts from which the Georgia CYVD strains were recovered were not associated with the subgroups. Interestingly, CYVD strain W01-A isolated from watermelon in Texas was more distant and fell outside the three subgroups. W01-A was the only CYVD strain recovered outside of Georgia and the only CYVD strain recovered from watermelon. Although BOX-PCR banding patterns can differentiate pathovars for some plant pathogens (Bull et al. 2011; Kaluzna et al. 2010), this is unlikely in this case because W01-A is pathogenic on pumpkin and squash (Bruton et al. 2003). Spatial distance and geographic isolation have been shown to contribute significantly to genetic variation in several microbial species, including the globally distributed Ralstonia solanacearum (Castillo and Greenberg 2007; Papke and Ward 2004). The observed genetic diversity suggests that the CYVD pathogen has been present in Georgia long enough for some strain diversification to occur or that diverse strains were introduced into Georgia.

Of considerable interest is CYVD strain SB03, which was isolated from inside a squash bug and was determined to be pathogenic on pumpkin in this study. SB03 clustered with non-CYVD strains and was most closely related to ATCC 13880 based on BOX-PCR banding profiles. This unique relationship was further supported using ERIC-PCR, which indicated that the two strains were identical, although they clustered with other CYVD strains. Similar results were observed using MLSA, where SB03 was identical to all other CYVD strains at five of six loci but, at the icd locus, SB03 shared an identical sequence with ATCC13880 and was also aligned more closely to the rice endophyte than to other CYVD strains. MLSA and rep-PCR examine different regions of the genome; therefore, the relationship between SB03 and ATCC 13880 may be more complex than indicated by either method alone. One possibility is that recombination occurred between SB03 and a non-CYVD S. marcescens strain. Because some strains of $S$. marcescens function as plant endophtyes or insect pathogens, recombination with CYVD strains could have taken place at either of these locales (Gyaneshwar et al. 2001; Sikorowski et al. 2001). Further characterization of SB03, including sequencing and comparison of additional HKG, may help to determine whether SB03 is the result of one or more recombination events.
BOX-PCR provided more discriminatory power than MLSA, based on the HKG selected, to differentiate between CYVD strains. Although the use of MLSA with rep-PCR provided greater insight than the use of one method alone, there are distinct advantages in the use of MLST or MLSA to determine genetic relationships. In contrast to rep-PCR, MLSA generates a discrete data set based on the nucleotide sequences of known genes and allows for the accurate calculation of genetic distances. The results are portable and additional sequences can be added to the database as they become available.

This study demonstrates that all but one of the CYVD strains of $S$. marcescens were identical in all six HKG sequence segments examined using MLSA, suggesting that plant-pathogenic strains recently diverged from a single common ancestor. Although CYVD strains formed a separate clade from non-CYVD strains, BOX-PCR revealed genetic diversity among the Georgia CYVD strains and between CYVD strains from Georgia and Texas, indicating that the pathogen may have been present in Georgia before confirmation of the disease in 2012. CYVD strain SB03, which grouped more closely with ATCC 13880 using rep-PCR, and with ATCC 13880 and the rice endophyte R01-A at the icd locus using MLSA, could be the result of a recombination event between CYVD and non-CYVD strains. Further genomic and biological investigations of these and additional CYVD strains, including determination of pathogenicity-associated factors, may lead to a better understanding of the origins and diversity of this unique plant pathogen.

\section{Acknowledgments}

This work was funded through a Southern Sustainable Agriculture Research and Education grant and the University of Georgia College of Agricultural and Environmental Sciences. We thank J. Fletcher for providing bacterial strains, R. Walcott for valuable input and assistance, and M. Brewer for critique of this manuscript.

\section{Literature Cited}

Almeida, N. F., Yan, S., Cai, R., Clarke, C. R., Morris, C. E., Schaad, N. W., Schuenzel, E. L., Lacy, G. H., Sun, X., Jones, J. B., Castillo, J. A., Bull C. T., Leman, S., Guttman, D. S., Setubal, J. C., and Vinatzer, B. A. 2010 PAMDB, A multilocus sequence typing and analysis database and website for plant-associated microbes. Phytopathology 100:208-215.

Altschul, S. F., Gish, W., Miller, W., Myers, E. W., and Lipman, D. J. 1990. Basic local alignment search tool. J. Mol. Biol. 215:403-410.

Benson, D. A., Karsch-Mizrachi, I., Clark, K., Lipman, D. J., Ostell, J., and Sayers E. W. 2012. GenBank. Nucleic Acids Res. 40:D48-D53.

Bereswill, S., Bugert, P., Völksch, B., Ullrich, M., Bender, C. L., and Geider, K. 1994. Identification and relatedness of coronatine-producing Pseudomonas syringae pathovars by PCR analysis and sequence determination of the amplification products. Appl. Environ. Microbiol. 60:2924-2930.

Besler, K. R., and Little, E. L. 2015. First report of cucurbit yellow vine disease caused by Serratia marcescens in Georgia. Plant Dis. 99:1175.

Bost, S. C., Mitchell, F. L., Melcher, U., Pair, S. D., Fletcher, J., Wayadande, A., and Bruton, B. D. 1999. Yellow vine of watermelon and pumpkin in Tennessee. Plant Dis. 83:587.

Bruton, B., Fletcher, J., Pair, S., Shaw, M., and Sittertz-Bhatkar, H. 1998. Association of a phloem-limited bacterium with yellow vine disease in cucurbits. Plant Dis. 82:512-520.

Bruton, B., Mitchell, F., Fletcher, J., Pair, S., Wayadande, A., Melcher, U., Brady, J., Bextine, B., and Popham, T. 2003. Serratia marcescens, a phloemcolonizing, squash bug-transmitted bacterium: Causal agent of cucurbit yellow vine disease. Plant Dis. 87:937-944.

Bull, C. T., Clarke, C. R., Cai, R., Vinatzer, B. A., Jardini, T. M., and Koike, S. T. 2011. Multilocus sequence typing of Pseudomonas syringae sensu lato confirms previously described genomospecies and permits rapid identification of $P$. syringae pv. coriandricola and $P$. syringae pv. apii causing bacterial leaf spot on parsley. Phytopathology 101:847-858.

Byun, R., Elbourne, L. D. H., Lan, R. T., and Reeves, P. R. 1999. Evolutionary relationships of pathogenic clones of Vibrio cholerae by sequence analysis of four housekeeping genes. Infect. Immun. 67:1116-1124.

Castillo, J. A., and Greenberg, J. T. 2007. Evolutionary dynamics of Ralstonia solanacearum. Appl. Environ. Microbiol. 73:1225-1238.

Dice, L. R. 1945. Measures of the amount of ecologic association between species. Ecology 26:297-302.

Do, T., Gilbert, S. C., Clark, D., Ali, F., Parolo, C. F., Maltz, M., Russell, R. R., Holbrook, P., Wade, W. G., and Beighton, D. 2010. Generation of diversity in Streptococcus mutans genes demonstrated by MLST. PLoS One 5:e9073. 
Feng, J., Schuenzel, E. L., Li, J., and Schaad, N. W. 2009. Multilocus sequence typing reveals two evolutionary lineages of Acidovorax avenae subsp. citrulli. Phytopathology 99:913-920.

Gillis, A., Rodríguez, M., and Santana, M. 2014. Serratia marcescens associated with bell pepper (Capsicum annuum L.) soft-rot disease under greenhouse conditions. Eur. J. Plant Pathol. 138:1-8.

Gyaneshwar, P., James, E. K., Mathan, N., Reddy, P. M., Reinhold-Hurek, B., and Ladha, J. K. 2001. Endophytic colonization of rice by a diazotrophic strain of Serratia marcescens. J. Bacteriol. 183:2634-2645.

Hugh, R., and Leifson, E. 1953. The taxonomic significance of fermentative versus oxidative metabolism of carbohydrates by various gram negative bacteria. J. Bacteriol. 66:24-26.

Kaluzna, M., Ferrante, P., Sobiczewski, P., and Scortichini, M. 2010. Characterization and genetic diversity of Pseudomonas syringae from stone fruits and hazelnut using repetitive-PCR and MLST. J. Plant Pathol. 92:781-787.

Little, E. L., Bostock, R. M., and Kirkpatrick, B. C. 1998. Genetic characterization of Pseudomonas syringae pv. syringae strains from stone fruits in California. Appl. Environ. Microbiol. 64:3818-3823.

Louws, F. J., Rademaker, J. L. W., and de Bruijn, F. J. 1999. The three Ds of PCRbased genomic analysis of phytobacteria: Diversity, detection, and disease diagnosis. Annu. Rev. Phytopathol. 37:81-125.

Lupski, J. R., and Weinstock, G. M. 1992. Short, interspersed repetitive DNAsequences in prokaryotic genomes. J. Bacteriol. 174:4525-4529.

Maiden, M. C. J., Bygraves, J. A., Feil, E., Morelli, G., Russell, J. E., Urwin, R., Zhang, Q., Zhou, J. J., Zurth, K., Caugant, D. A., Feavers, I. M., Achtman, M., and Spratt, B. G. 1998. Multilocus sequence typing: A portable approach to the identification of clones within populations of pathogenic microorganisms. Proc. Natl. Acad. Sci. USA 95:3140-3145.

Morris, C. E., Bardin, M., Kinkel, L. L., Moury, B., Nicot, P. C., and Sands, D. C. 2009. Expanding the paradigms of plant pathogen life history and evolution of parasitic fitness beyond agricultural boundaries. PLoS Pathog. 5: e1000693.

Pair, S. D., Bruton, B. D., Mitchell, F., Fletcher, J., Wayadande, A., and Melcher, U. 2004. Overwintering squash bugs harbor and transmit the causal agent of cucurbit yellow vine disease. J. Econ. Entomol. 97:74-78.

Papke, R. T., and Ward, D. M. 2004. The importance of physical isolation to microbial diversification. FEMS Microbiol. Ecol. 48:293-303.

Patchanee, P., Chokboonmongkol, C., Zessin, K. H., Alter, T., Pornaem, S., and Chokesajjawatee, N. 2012. Comparison of multilocus sequence typing (MLST) and repetitive sequence-based PCR (rep-PCR) fingerprinting for differentiation of Campylobacter jejuni isolated from broiler in Chiang Mai, Thailand. J. Microbiol. Biotechnol. 22:1467-1470.

Rascoe, J., Berg, M., Melcher, U., Mitchell, F. L., Bruton, B. D., Pair, S. D., and Fletcher, J. 2003. Identification, phylogenetic analysis, and biological characterization of Serratia marcescens strains causing cucurbit yellow vine disease. Phytopathology 93:1233-1239.
Reguera, G., and Kolter, R. 2005. Virulence and the environment: A novel role for Vibrio cholerae toxin-coregulated pili in biofilm formation on chitin. J. Bacteriol. 187:3551-3555.

Sikora, E. J., Bruton, B. D., Wayadande, A. C., and Fletcher, J. 2012. First report of the cucurbit yellow vine disease caused by Serratia marcescens in watermelon and yellow squash in Alabama. Plant Dis. 96:761.

Sikorowski, P. P., Lawrence, A. M., and Inglis, G. D. 2001. Effects of Serratia marcescens on rearing of the tobacco budworm (Lepidoptera: Noctuidae) Am. Entomol. 47:51-60.

Tamura, K., Stecher, G., Peterson, D., Filipski, A., and Kumar, S. 2013. MEGA6: Molecular Evolutionary Genetics Analysis Version 6.0. Mol. Biol. Evol. 30 2725-2729.

Tan, Z. Y., Hurek, T., Gyaneshwar, P., Ladha, J. K., and Reinhold-Hurek, B. 2001 Novel endophytes of rice form a taxonomically distinct subgroup of Serratia marcescens. Syst. Appl. Microbiol. 24:245-251.

Untergasser, A., Cutcutache, I., Koressaar, T., Ye, J., Faircloth, B. C., Remm, M., and Rozen, S. G. 2012. Primer3-New capabilities and interfaces. Nucleic Acids Res. 40:e115.

Versalovic, J., Schneider, M., Bruijn, F., and Lupski, J. R. 1994. Genomic fingerprinting of bacteria using repetitive sequence-based polymerase chain reaction. Methods Mol. Cell. Biol. 5:25-40.

Wang, X.-Q., Bi, T., Li, X.-D., Zhang, L.-Q., and Lu, S.-E. 2015. First report of corn whorl rot caused by Serratia marcescens in China. J. Phytopathol. 163: 1059-1063.

Wei, G., Kloepper, J. W., and Tuzun, S. 1996. Induced systemic resistance to cucumber diseases and increased plant growth by plant growth-promoting rhizobacteria under field conditions. Phytopathology 86:221-224.

Wick, R. L., Lerner, J., Pair, S. D., Fletcher, J., Mitchell, F., and Bruton, B. D. 2001. Detection of cucurbit yellow vine disease in squash and pumpkin in Massachusetts. Plant Dis. 85:1031-1031.

Wirth, T., Falush, D., Lan, R. T., Colles, F., Mensa, P., Wieler, L. H., Karch, H. Reeves, P. R., Maiden, M. C. J., Ochman, H., and Achtman, M. 2006. Sex and virulence in Escherichia coli: An evolutionary perspective. Mol. Microbiol. 60:1136-1151.

Young, J. M., Park, D. C., Shearman, H. M., and Fargier, E. 2008. A multilocus sequence analysis of the genus Xanthomonas. Syst. Appl. Microbiol. 31: 366-377.

Zhang, Q., Melcher, U., Zhou, L., Najar, F. Z., Roe, B. A., and Fletcher, J. 2005. Genomic comparison of plant pathogenic and nonpathogenic Serratia marcescens strains by suppressive subtractive hybridization. Appl. Environ. Microbiol. 71:7716-7723.

Zhang, Q., Weyant, R., Steigerwalt, A. G., White, L. A., Melcher, U., Bruton, B. D., Pair, S. D., Mitchell, F. L., and Fletcher, J. 2003. Genotyping of Serratia marcescens strains associated with cucurbit yellow vine disease by repetitive elements-based polymerase chain reaction and DNA-DNA hybridization. Phytopathology 93:1240-1246. 